IJMS 18 (1), 99-115 (2011)

\title{
THE FAMILY AS A SOCIOECONOMIC MANAGEMENT SYSTEM
}

\author{
MASUDUL ALAM CHOUDHURY* \\ College of Commerce and Economics \\ Sultan Qaboos University, Muscat \\ Sultanate of Oman \\ *The School of Business \\ Cape Breton University, Canada
}

\begin{abstract}
The family is a social miniscule in every culture. It is a central theme of gender-development issue. As such it has a distinct and abiding effect on the nature of the socioeconomic order in terms of preference formation relating to the kinds of artifacts that get exchanged and thus play a key role in socioeconomic development. The totality of these issues comprises the study of the family as a socioeconomic management system. The intergenerational interaction and co-evolution of the family in concert with the social complex is differently explainable in neoclassical economic and Islamic contexts. Consequently, the triangular circular interrelationships between the individual, the household and the socioeconomic order leave different effects in the above two paradigms. These in turn have profound influence on the future of socioeconomic development according to these paradigms. This paper formalizes an interrelationship between the inter-generational family and the socioeconomic order using the concept of circular causation of unity of knowledge in Islam and the methodological individualism in neoclassical economic theory. The intertemporal context of the theme is included with family extensions and their socioeconomic effects over populations of grandfathers and grandchildren.
\end{abstract}

Keywords: Microeconomics of family, socioeconomic management system, inter-generational endogenous preferences, culture and political economy.

\section{Background and Objective}

The individual and the household are the formative springs of socioeconomic relations at large, particularly in respect of genderdevelopment issues. Such issues when studied in the context of self 
and institutional linkages assume the texture within management science, that is, the interactive decision-making in the family as a great institution are studied in the light of attaining the goals of perceived meaning of altruistic wellbeing. In such interaction, parents and children, their further lineage to extended family members, the community and inter-generationally, assume critical perspectives. Preferences behaviour and its study by mathematical mappings becomes rigorous scientific examination. Thus to study the family as an institution endowed by an objective goal and a system of interaction res extensa, involving preferences in their various forms of individual and family-related behaviour, convey the meaning of socioeconomic management system. In this paper we will undertake such a scientific study of the family as a socioeconomic management system.

In treating these agents as a social miniscule it is important to understand how the attitudes and values of the individual form the household and these then interact with the community and the socioeconomic order. Such a relationship in turn translates into socioeconomic development, which progressively can transcend to the national and global levels intra- and inter-generationally. Such ideas on community economic development have been highlighted recently by studies at the World Bank (2001) and UNDP (2000).

We will refer to the formation of values and attitudes at the microeconomic level as preference formation (Debreu, 1959). The study of preference formation will include our investigation of familial behaviour formed by and in turn affecting individual-familysocioeconomic decision-making and the nature of interaction in the contrasting paradigms of neoclassical economics and Islam.

Firstly, we will examine the economics of the family in the light of neoclassical economic theory a la Becker (1989). This theory is criticized in view of its loss of interactive process due either to methodological individualism or dominant hegemony of a decision maker. Consequently, we will show that the causal relationships between the individual, household, and labour market and community socioeconomics are governed by and in turn generate similar kinds of relationships premised on methodological individualism and hegemony (Ben-Porath, 1980).

Secondly, we will present the contrasting theory of interactive preference formation of individuals within the family both intra- and inter-generationally (Choudhury, 1996). This approach is contrary to the neoclassical meaning of utilitarian values and methodological individualism. Consequently, the circular causal interrelationships between individuals, households and the socioeconomic order will 
accordingly be of an interactive and co-evolutionary type. To study this formalism we will introduce a methodological framework of analysis, which we will refer to as the interactive, integrative and evolutionary (IIE) model of unity of knowledge in the systems context (Choudhury, 1995). Reference to such a model is derived from the centrally governing premise of oneness of God in Islamic belief and conduct of life and thought. The precept of divine oneness is interpreted here in terms of a systemic unity of knowledge (i.e. participation, complementarities and linkages) as established by the Qur'an (Choudhury, 1999).

\section{A Socioeconomic Definition of Family}

A family is a collection of individuals bound together by blood relations, values and fealty. Thus they pursue some common wellbeing objectives through patterns of decision-making that interconnects individual members with the head of the family and extended families in the inter-generational sense. The relationship is circularly causal and thus strongly interactive. The values inculcated within the family are interdependent with the social structure by multiple interrelations. Decision-making within the family on various issues in concert with socioeconomic matters involves allocation of time according to the distribution of tasks by the members.

\section{The Neoclassical Economic Theory of the Household and Its Social Impact: A Critique}

In the light of the above definition, neoclassical economic theory treats the individual in relation to the family in terms of utilitarian motives. Three cases can be examined here to make the general observation on the nature of familial relationship, preference formation and the wellbeing criterion.

1. Each individual in the family is seen as an individualist with rights, freedoms and privileges of its his or her own. This case can be seen with children and parents who each seek their own individual wellbeing out of secured rights within and outside of home. Children exercise their rights to decide individually to remain independent of parents after the dependency age. The same attitude can be found in the common-law family by virtue of an absence of legal rights binding any side for a mutual sharing of economic benefits. Such a picture of individualist attitudes and values that transcend from individual behaviour to the social structure is referred to as methodological individualism (Brennan \& Buchanan, 2000).

IJMS 18 (1), 99-115 (2011) 101 
We formalize the above characteristics for the individual and family in neoclassical economic context: Let the ith individual preference map used to preorder a set of rational preferences of choices be denoted by $\geq, \mathrm{i}=1,2, ., \mathrm{n}$. Consider the three choices; A (decision not to bear children followed by increased labour force participation), B (decision in favour of both childbearing and work participation), and $\mathrm{C}$ (child bearing and homemaking). Individuals in a family governed by methodological individualism will likely preorder preferences as $\mathrm{A} \geq_{\mathrm{i}} \mathrm{B} \geq_{\mathrm{i}} \mathrm{C}$.

The collective preferences of the family governed by methodological individualism are firstly spread over socioeconomic states and the number of i-individuals:

$$
\cup_{i} \cup_{\text {states }}\left\{\geq_{i}[A, B, C]\right\}=\cup_{i}\left[\geq_{i}(A)+\geq_{i}(B)+\geq_{i}(C)\right], i=1,2, . ., n .
$$

If for a larger number of individuals $\mathrm{i}$, state $\mathrm{A}$ dominates in the preordering as shown, then $\geq_{i}(B)$ and $\geq_{i}(C)$ become decreasingly relevant preferences (irrelevant preference in the limit (Arrow, 1951). Now preferences $\geq_{i}$ (A) dominate over all other preferences. Consequently, social preference $(\geq)$ arising from the household is reflected in $\cup_{i}\left[z_{i}(A)\right]=\geq(A)$ say, now independent of $i$ due to the dominance of the principal preference.

Next apply ith individual utility index in hth household, $\mathrm{U}_{\text {ih }}$ to $\geq$ to yield the above form of aggregation leading to the household utility function, $\mathrm{U}_{\mathrm{h}}$ :

$$
\mathrm{U}_{\mathrm{h}}=\Sigma_{\mathrm{i}} \mathrm{U}_{\text {ih }}(\geq(\mathrm{A})) \text {, with } \mathrm{U}_{\text {ih }}(\geq(\mathrm{A}))>\mathrm{U}_{\text {ih }}(\geq(\mathrm{B}))>\mathrm{U}_{\text {ih }}(\geq(\mathrm{C})) \text {, }
$$

over the three states.

Hence, utility maximization objective of neoclassical household utility function rests simply on $\mathrm{U}_{\mathrm{ih}}(\geq(\mathrm{A})$ ).

From this level, the social welfare function in which the family is a social miniscule, is given by $\mathrm{U}(\mathrm{A})$ :

$$
\mathrm{U}(\mathrm{A})=\Sigma_{\mathrm{h}} \mathrm{U}_{\mathrm{h}}=\Sigma_{\mathrm{h}} \Sigma_{\mathrm{i}} \mathrm{U}_{\mathrm{ih}}(\geq(\mathrm{A})) .
$$

Corresponding to the rational choice, A causes continuous substitution of the variables characterizing A over those characterizing $B$ and $C$ for individuals, households and society, since preferences are now replicated in additive fashion. 
2. In the second case we consider the possibility of distributed choices between A,B,C. Now household members' behaviour as described above results in the social utility function of the type shown in expression (3). The formal steps towards establishing it have been skipped, but the implications are important to note.

$$
\mathrm{U}(\mathrm{A})=\Sigma_{\mathrm{h}} \mathrm{U}_{\mathrm{h}}=\Sigma_{\mathrm{h}} \Sigma_{\mathrm{i}} \mathrm{U}_{\mathrm{ih}}(\geq(\mathrm{A}), \geq(\mathrm{B}), \geq(\mathrm{C})) .
$$

Its own bundle of goods and services that serve individual needs within a household determines each of the states A, B and C. For instance, A can be characterized by work participation, B by daycare, $\mathrm{C}$ by home-cared goods. These goods exist as substitutes of each other either taken individually or in groups. For instance, A can combine with $B$ in the form of cost-effective daycare. The bundles of goods work in participation with daycare in the choice $(\mathrm{A}, \mathrm{B})$, and thereby substitute C. Socially, this choice is made to reflect the needs of A and $\mathrm{B}$ and to formulate both market goods and institutional policies that promote $A$ over $B$ over $C$, or $(A, B)$ over $C$, as the case may be.

3. Resource allocation over the alternatives A, B and C requires time and income. The allocation of income and time over such activities forms the budget constraint for utility maximization in the above two cases.

We formalize such resource allocation as follows: Let total household time be allocated to leisure (childbearing, $\mathrm{c}$ ) and works (productive activity, w).

The cost for acquiring $\mathrm{c}$ is $\mathrm{C}_{\mathrm{c}^{\prime}}$ the cost for acquiring $\mathrm{w}$ is $\mathrm{C}_{\mathrm{w}}$. Total allocation of time between household and work activities denoted by $\mathrm{T}$ is given by the following expression:

$$
\mathrm{T}=\mathrm{t}_{\mathrm{c}}+\mathrm{t}_{\mathrm{w}}
$$

Income constraint is, $\mathrm{I}=\mathrm{t}_{\mathrm{c}} \cdot \mathrm{C}_{\mathrm{c}}+\mathrm{t}_{\mathrm{w}} \cdot \mathrm{C}_{\mathrm{w}}$

This equation shows that income I is monetarily allocated as spending over the total time used in household activity plus spending in the total allocation of time spent in work activity. 
The household utility maximization problem is now stated as,

$$
\begin{array}{ll} 
& \text { Max. }\left[\mathrm{U}_{\mathrm{h}}\left(\mathrm{t}_{\mathrm{c},} \mathrm{t}_{\mathrm{w}}\right)=\sum_{\mathrm{i}} \mathrm{U}_{\mathrm{ih}}(\mathrm{A}, \mathrm{B}, \mathrm{C})\right]^{1} \\
\text { Subject to, } & \mathrm{I}=\mathrm{t}_{\mathrm{c} .} \mathrm{C}_{\mathrm{c}}+\mathrm{t}_{\mathrm{w}} \cdot \mathrm{C}_{\mathrm{w}}=\sum_{\mathrm{i}}\left(\mathrm{t}_{\mathrm{ci}} \cdot \mathrm{C}_{\mathrm{ci}}+\mathrm{t}_{\mathrm{wi}} \cdot \mathrm{C}_{\mathrm{wi}}\right) \\
& \mathrm{T}=\mathrm{t}_{\mathrm{c}}+\mathrm{t}_{\mathrm{w}}=\sum_{\mathrm{i}}\left(\mathrm{t}_{\mathrm{ci}}+\mathrm{t}_{\mathrm{wi}}\right)
\end{array}
$$

We have now two versions of the above household maximization problem. They together have important underlying implications: household and social preferences are social replicas of individual preferences, values and attitude toward the family. The individual utility indexes, and thereby, the household utility function and the social welfare function, are each based on competing attitude towards goods distributed between substitutes A, B and C in the sense as mentioned earlier. Preferences are uniformly competing, preordered and individualistic in type.

4. In expression (4) the household utility function and the social welfare function convey all the utilitarian constructs given by Becker (Becker, 1981) as follows.

a. Household utility function is based on marginal substitution between children as leisure and market goods. The utility function is of the form (1).

b. The number of children and the quality of children experience a tradeoff in the utility function with quality included.

c. Children's utility and the consumption of parents are substitutes as expressed by the utility forms in either expression (1) or (3).

d. In the utility function of the head of the family with multiple children's goods the head of the family needs more income to augment a gift to the children and the wife in such a way that there is compensation between other members so as to keep a sense of fairness in the income distribution between members and also spending it himself. The utility function is of the form (4) with the addition of the cost of gift. Time allocation in generating income for gifts is usually added to or treated similar to $t_{w}$. The assumption of marginal rates of substitutions between goods for children is that cheating children increase the cost of the head of family by the amount of additional income required for gifts.

e. The utility function in form (4) can be taken up separately for the husband and the wife to explain Becker's theory of marriage and divorce (Becker, 1974). If the gift (bribe) 
given by the wife to the husband is deducted from the wife's income in marriage and the net income of the wife while married exceeds the family income if divorced, the decision of the wife is to remain in marriage. The same argument is extended to the husband's side.

In all cases we find that the specific nature of methodological individualism, preordered preferences, competition and marginal substitution property of every utility function causes a hedonic household and a society of individuals as cold calculators.

The laterally and independently aggregated preferences of household members are continued inter-generationally to form an extension of the above formalization to this latter case. The socioeconomic character premised on the inter-generational family preferences acts as a catalyst for its continuity.

\section{Preference Behaviour of the Islamic Household and Its Socioeconomic Impact}

In contrast, the Islamic way of life, attitude, motivation and thus preferences are centrally guided by the principle of unity of knowledge. That is, in this system knowledge is derived from the divine text that forms, guides and sustains behaviour. The guidance takes the form of mobilizing certain instruments as recommended by the Islamic Law (Shari'ah) that establish unity of knowledge as a participatory and cooperative conduct of decision-making at all levels. The instruments used assist in such participatory and cooperative decision-making while they phase out the instruments of self-interest, individualism, competition and methodological independence between the partners.

The family as a social miniscule becomes a strong source for the realization of the participatory decision-making emanating from knowledge-induced preference formation. As in every other area of human involvement the family forms its preferences by interaction and consensus involving members. The result of interaction is consensus (integration) based on discourse and participation within and across members and the socioeconomic order. Such an interactively developed integration is the idea of a systemic meaning of unity of knowledge. Thirdly, the enhancement of knowledge by interaction and integration is followed by evolutionary knowledge. The three phases of interaction, integration and co-evolution (IIE) continue over the processes of learning (hence evolutionary knowledge formation). The socioeconomic order caused and sustained by such a systemic

IJMS 18 (1), 99-115 (2011) 105 
IIE-dynamics responds in a similar way. We refer to such a discursive process as being premised on unity of knowledge. Its epistemology and application by appropriate instruments are premised on the law of oneness of God (i.e. or unity of divine law).

An example of the Islamic familial attitude is the respect between the young and the old, and between husband and wife inter-generationally speaking. In this system the Qur'an says that men and women are cooperators with each other and children form a social bond ordained by God (Qur'an 7:189-90). Within this familial relationship there exists the spirit of discourse and understanding enabling effective decision-making. The participatory experience is realized in such a case through the Islamic medium of participation and consultation called the Shura. The Shura process of decision-making is the same as the IIE-learning process.

The IIE-learning process being a nexus of co-evolutionary movements in unity of systemic knowledge, it spans over space (socioeconomic order) and time (inter-generational). In the socioeconomic extension the IIE-process applies to matters of individual preferences, freedom of choice, participatory production environment, appropriateness of work participation, distribution of wealth, caring for orphans, trusts, inheritance, contractual obligations, marriage, divorce, social consequences of goodness, and unethical conduct. The socioeconomic variables are thus activated by the induction of the moral and ethical values premised on unity of knowledge as the relational epistemology and realized by appropriate participatory instruments that enable social co-determination, voluntary conduct, attitudes, contracts and obligations. Both the episteme and the instruments of application of unity of knowledge emanate from the law of divine oneness, now understood in the system sense of complementarities and participation caused by circular causation interrelations.

\section{Formalizing Preference Formation in the Islamic Family}

Let $\left\{z_{i, k, h}\right\}^{i}=\left\{z_{i, h} \cap z_{k, h}\right\}^{i}$ denote the interactive preferences of the jth individual (k-individual) in the hth household, $\mathrm{j}, \mathrm{k}=1,2, . ., \mathrm{n}$; $\mathrm{h}=$ $1,2, \ldots, \mathrm{m}$; i denotes the number of inter-member interaction on given issues. Let the jth (kth) preference be of a specific (hth) head-of-the family.

The household preference, $\geq_{\mathrm{h}}=\lim _{\mathrm{i}}\left[\left\{\cup_{\mathrm{j}, \mathrm{k}} \geq_{\mathrm{j}, \mathrm{k}, \mathrm{h}}\right]^{\mathrm{i}}\right]=\lim _{\mathrm{i}}\left[\left\{\cup_{\mathrm{j}, \mathrm{k}}\left\{\geq_{\mathrm{i}, \mathrm{h}} \cap \geq_{\mathrm{k}, \mathrm{h}}\right\}^{\mathrm{i}}\right]\right.$ is the mathematical union of the above individual preference map over $(\mathrm{j}, \mathrm{k})$ for i-interaction.

106 IJMS 18 (1), 99-115 (2011) 
The social preference $\geq$ equals aggregation of h-household preferences:

$$
\left.\geq=\cup_{h} \geq_{h}=\cup_{h} \lim _{\mathrm{i}}\left[\cup_{\mathrm{j}, \mathrm{k}}\left(\geq_{\mathrm{j}, \mathrm{k}, \mathrm{h}}\right)\right\}^{\mathrm{i}}\right]=\cup_{\mathrm{h}} \lim _{\mathrm{i}}\left[\left\{\cup_{\mathrm{j}, \mathrm{k}}\left\{\geq_{\mathrm{j}, \mathrm{h}} \cap \geq_{\mathrm{k}, \mathrm{h}}\right\}^{\mathrm{i}}\right] .\right.
$$

This expression shows that social preferences are formed interactively (shown by $\cap$ ) and integratively (shown by $\lim _{i}\left\{\cup_{j, k}(\right.$.$) ) in given rounds$ of family discourse (i) on issues of common interest.

Because interactions leading to integration cause the formation of knowledge, we will denote such a knowledge formation by $\theta_{\mathrm{h}}{ }^{\mathrm{i}}$, for hth household and i number of interactions. ' $i$ ' takes up increasing sequential numbers as interaction and integration proceed on into evolutionary phases of learning by discourse. The limiting value of knowledge-flows over a given process of IIE may be denoted by $\theta_{h}{ }^{i *}$. The limiting social value of knowledge-flows in terms of interactions concerning many goods and services that are shared in the market, and are ethically determined by IIE-type preference formation across

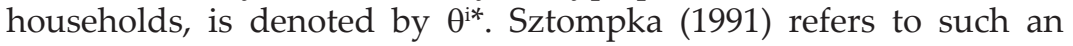
evolutionary social experience as social becoming.

As i increases (numbered processes), a case typically encountered when more members of the extended family are involved in a household decision-making, an evolutionary phenomenon is experienced. This completes the IIE-learning pattern over many processes. Such is the inter-generational implication of extension of the IIE-processes over space (socioeconomics) and time (inter-generational).

\section{Model of the Family as a Social Miniscule}

The family as a social miniscule is now defined by the collection of all households deciding in the IIE-learning process over given socioeconomic issues. Let such socioeconomic bundles for the hth household with $1,2, \ldots$ members and the head of the family be denoted by $\mathbf{x}_{\mathrm{h}}{ }^{\mathrm{i}}=\left\{\mathrm{x}_{1 h^{\prime}}, \mathrm{x}_{2 \mathrm{~h}^{\prime}}, \ldots, \mathrm{x}_{\mathrm{in}}, \ldots\right\}^{\mathrm{i}}$. Let $\mathrm{c}_{\mathrm{h}}{ }^{\mathrm{i}}=\left\{\mathrm{c}_{1 h^{\prime}}, \mathrm{c}_{2 \mathrm{~h}^{\prime}}, \ldots, \mathrm{c}_{\mathrm{jh}}, \ldots\right\}^{\mathrm{i}}$ denote the unit cost of acquiring $\mathbf{x}_{\mathbf{h}}{ }^{i}$. The influence of interaction is denoted by the presence of ' $i$ '. Thereby, the household spending in acquiring its bundle of goods is given by $\mathbf{c}_{\mathrm{h}}{ }^{\mathrm{i}} \cdot \mathbf{x}_{\mathrm{h}}{ }^{\mathrm{i}}=\Sigma_{\mathrm{k}}\left(\mathrm{x}_{\mathrm{kh}} \cdot \mathrm{C}_{\mathrm{kh}}\right)^{\mathrm{i}}=\mathrm{Sp}_{\mathrm{h}}{ }^{\mathrm{i}}$, where, $S \mathrm{p}_{\mathrm{h}}{ }^{\mathrm{i}}$ denotes the total spending of $\mathrm{k}$-members of the hth household over a given series of interaction $i$. Spending on the good things of life is highly encouraged in the Qur'an as opposed to saving and hoarding as withdrawal from the social economy.

The family member's $\mathrm{j}, \mathrm{k}$ interactive attainment of well-being in h-household is, 


$$
\mathrm{W}_{\mathrm{jk}}{ }^{\mathrm{i}}\left(\theta_{\mathrm{h}}{ }^{\mathrm{i} *}, \operatorname{Sp}_{\mathrm{kh}}{ }^{\mathrm{i}}\left(\theta_{\mathrm{h}}{ }^{\mathrm{i} *}\right)\right)\left[\operatorname { l i m } _ { \mathrm { i } } \left[\left\{\cup_{\mathrm{j}, \mathrm{k}}\left\{\geq_{\mathrm{j}, \mathrm{h}} \cap \geq_{\mathrm{k}, \mathrm{h}}{ }^{\mathrm{i}}\right]\right.\right.\right.
$$

The bracketed term [.] throughout this paper means the implied induction of this constituent term on all the variables, relations and functions.

The simulation problem for the interacting $(\mathrm{j}, \mathrm{k})$-individual over $\mathrm{i}$-interaction for a given h-household is given by:

$$
\begin{aligned}
& \text { Simulate } \quad \mathrm{W}_{\mathrm{jk}^{\mathrm{i}}}\left(\theta_{\mathrm{h}^{\mathrm{i}}}, \operatorname{Spkh}_{\mathrm{kh}}\left(\theta_{\mathrm{h}^{*}}\right)\right)\left[\operatorname { l i m } \mathrm { i } \left[\left\{\cup_{\mathrm{j}, \mathrm{k}}\left\{\geq_{\mathrm{j}, \mathrm{h}} \cap \geq_{\mathrm{k}, \mathrm{h}}\right\}^{\mathrm{i}}\right]\right.\right.
\end{aligned}
$$

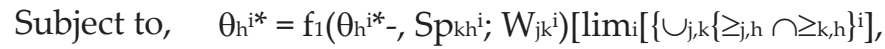

$$
\begin{aligned}
& \text { '-' denoting one-process lag in the IIE-processes, given a } \\
& \text { simulated value of } \mathrm{W}_{\mathrm{jk}}{ }^{\mathrm{i}} \text { in any ith-process. }
\end{aligned}
$$$$
\mathrm{Sp}_{\mathrm{kh}}{ }^{\mathrm{i}}=\mathrm{f}_{2}\left(\theta_{\mathrm{h}}{ }^{\mathrm{i} *} ; \mathrm{W}_{\mathrm{jk}}{ }^{\mathrm{i}}\right)\left[\operatorname { l i m } _ { \mathrm { i } } \left[\left\{\cup _ { \mathrm { j } , \mathrm { k } } \left\{\left\{z_{\mathrm{j}, \mathrm{h}} \cap\left\{\geq_{\mathrm{k}, \mathrm{h}}\right\}^{\mathrm{i}}\right]\right.\right.\right.\right. \text { is the spending of }
$$$$
\text { kth individual in the hth household. }
$$

After taking the mathematical union of all relations concerning k-individuals in h-household, simulation of the total h-household members' well-being function is given by,

$$
\begin{array}{ll}
\text { Simulate }_{\left\{\text {thi*\} }^{i *}\right.} & \mathrm{W}_{\mathrm{h}}{ }^{\mathrm{i}}\left(\theta_{\mathrm{h}}{ }^{\mathrm{i} *}, \mathrm{Sp}_{\mathrm{h}}{ }^{\mathrm{i}}\left(\theta_{\mathrm{h}}{ }^{\mathrm{i} *}\right)\right)\left[\left\{z_{\mathrm{h}}\right]\right. \\
\text { Subject to, } & \theta_{\mathrm{h}}{ }^{\mathrm{i}}=\mathrm{f}_{1}\left(\theta_{\mathrm{h}}{ }^{\mathrm{i} *}-, \mathrm{Sp}_{\mathrm{h}}{ }^{\mathrm{i}} ; \mathrm{W}_{\mathrm{h}}{ }^{\mathrm{i}}\right)\left[\left\{z_{\mathrm{h}}\right]\right. \\
& \mathrm{Sp}_{\mathrm{h}}{ }^{\mathrm{i}}=\mathrm{f}_{2}\left(\theta_{\mathrm{h}}{ }^{\mathrm{i} *} ; \mathrm{W}_{\mathrm{h}}{ }^{\mathrm{i}}\right)\left[\left\{z_{\mathrm{h}}\right]\right.
\end{array}
$$

Clearly, (6) is derived by the mathematical union of every part of (5) over all h-household individuals. By a further mathematical union of every part of (6) over all households we obtain the simulation problem of the social well-being function,

$$
\begin{array}{ll}
\text { Simulate }_{\left\{\theta^{*}\right\}} & \mathrm{W}^{\mathrm{i}}\left(\theta^{\mathrm{i} *}, \mathrm{Sp}^{\mathrm{i}}\left(\theta^{\mathrm{i}}\right)\right)[ \\
\text { Subject to, } & \theta^{\mathrm{i} *}=\mathrm{f}_{1}\left(\theta^{\mathrm{i*}}-, \mathrm{Sp}^{\mathrm{i}} ; \mathrm{W}^{\mathrm{i}}\right)[\{] \\
& \mathrm{Sp}^{\mathrm{i}}=\mathrm{f}_{2}\left(\theta^{\mathrm{i*}} ; \mathrm{W}^{\mathrm{i}}\right)[\{]
\end{array}
$$

Since $\theta$-values are central to the simulation problem, learning is extended over space and time to embrace such inter-generational knowledge-flows and the corresponding knowledge-induced variables. The ethical and moral preferences of inter-generational members of the family thus remain intact in order to sustain the effectiveness of the IIE-learning process in concert with the intergenerational family and the socioeconomic order. 


\section{Refinements in the Household and Social Well-being Function}

In participatory decision-making (Shura as IIE-learning process) the role of the revered and learned principal (Amir) is central. The Amir is a head of high knowledge and integrity in the Islamic Law, Shari'ah. The guidance of the head in decision-making is respected. It is instrumental in guiding discourse and decision-making among members. The Islamic family members are required to respect but not follow the injunctions of the head of the family in case such a decision is contrary to Islamic Law.

Given the head $(\mathrm{H})$ of the family's well-being function, $\mathrm{W}_{\mathrm{H}}^{\mathrm{Ni}}$ as a reference for household decision-making, the new simulation problem derived in the manner of (7) takes the form,

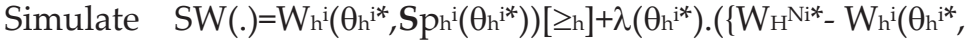

$$
\begin{aligned}
& \left.\left.\operatorname{Sph}^{\mathrm{i}}\left(\theta \mathrm{h}^{\mathrm{i}}\right)\right)[\geq \mathrm{h}]\right\}
\end{aligned}
$$

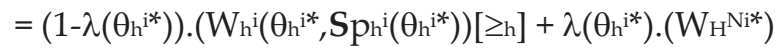

$$
\begin{aligned}
& \operatorname{Sph}^{\mathrm{i}}=\mathrm{f}_{2}\left(\theta_{\mathrm{h}^{\mathrm{i}}} ; \mathrm{Wh}_{\mathrm{h}} \mathrm{i}\right)[\mathrm{Zh}]
\end{aligned}
$$

$\mathrm{W}_{\mathrm{H}}^{\mathrm{Ni*}}$ is an assigned level of the head's perception of the well-being function for the family. It assumes a form explicit or implicit through the household IIE-learning process after $\mathrm{N}_{\mathrm{i}}$ rounds of discourse. Thus, $\left(\left\{\mathrm{W}_{\mathrm{H}}{ }_{\mathrm{Ni}}{ }^{\mathrm{i} *}-\mathrm{W}_{\mathrm{h}}{ }_{\mathrm{i}}^{\mathrm{i}}\left(\theta_{\mathrm{h}}{ }^{\mathrm{i} *}, \mathrm{Sp}_{\mathrm{h}}{ }^{\mathrm{i}} \theta_{\mathrm{h}}{ }^{\mathrm{i} *}\right)\right)\left[\geq_{\mathrm{h}}\right]\right.$ is an adaptive constraint. $\lambda\left(\theta_{\mathrm{h}}{ }^{\mathrm{i} *}\right)$ in $0<\lambda\left(\theta_{\mathrm{h}}^{\mathrm{i} *}\right)<1$ explains simulative knowledge-induced shifts in the well-being index as an attribute of knowledge-induction in the IIEprocesses.

Evaluation of the resultant social well-being function determines the ethical transformation of the socioeconomic order caused by the Islamic choices of goods and services at the household level. The result is generalizable inter-generationally.

Simple manipulation of the model (8) yields $d S W / d \theta_{h}{ }^{i *}>0$ with all the terms resulting from the differentiation being positive. The magnitude of the positive sign will be determined by the sign of $\left[W_{H}^{\text {Ni* }}(.)-.W_{h}^{i *}().\right]$. If this term is positive, this positive value of $\mathrm{dSW} / \mathrm{d} \theta_{\mathrm{h}}{ }^{\mathrm{i}}$ will be higher than the positive value of the same if the term is negative. This means that the effective guidance, governance and caring attitude of the heads (principals) of the inter-generational family over the members are a pre-condition for the sustainable wellbeing of the family. In turn, such attitudes of all households determine the increased level of social well-being. 
We note that an increase in $\mathrm{W}_{\mathrm{H}}^{\mathrm{Ni} *}(.$.$) due to a gain of knowledge$ derived from organic complementarities within and across family decision-making in concert with the socioeconomic order must remain higher than the similar gain in $\mathrm{W}_{\mathrm{h}}^{\mathrm{i} *}(.$.$) . This marks continuity$ of the patriarchal family and the caring function of the principal. The conviction on the positive role of spending in the good things of life on social well-being is a basis of motivation of the principal on family members' well-being. Sustainability of such a family socioeconomic response needs to be sustained inter-generationally.

\section{Important Properties of the Simulation Models of Individual- Family-Markets}

We note a few important properties of the above simulation systems. First, continuous sequencing of the IIE-learning phases explains the dynamic creation of knowledge. Secondly, the creative evolution of knowledge-flows is determined by behavioural aspects of the model as explained by the IIE-learning type preference formation. Thirdly, the IIE-learning nature of individual preferences transmits the same characteristics to the socioeconomic variables through household preferences. Hence the household is seen to be a social miniscule. Fourthly, the aggregation of the social well-being index from the individual and household levels to the social level is non-linear. Likewise the simulation constraints are nonlinear. That is because of the continuous knowledge-induction caused by complementarities between the diverse variables. Besides, the functional coefficients are knowledge-induced causing shifts in the well-being function and the constraints over the IIE-learning processes.

\section{Inferences from the Contrasting Paradigms}

The neoclassical and Islamic socioeconomics of the family give contrasting paradigms and behavioural results. Neoclassical economics is built on hedonic preferences. Methodological individualism starts from the behavioural premise that is essentially formed in the household according to an epistemic background. The households in neoclassical socioeconomics manifest intensifying individualistic views by the very epistemological basis of economic and social reasoning. Consequently, the family as a social miniscule also transmits the same nature of preferences and individualism to the socioeconomic order. The meaning of interaction is mentioned without a substantive content in dynamic preference formation. A substantive methodology of participatory process in decision-making 
is thus absent in neoclassical economics. In this paper dynamic preference formation by a learning process is treated equivalently with endogenous preferences. They cause learning in the family both intra-generationally and inter-generationally, and in similar relations with the socioeconomic environment.

\section{The Socioeconomic Consequences of the Neoclassical Case}

The institutional and policy implications of the above behavioural consequences of the neoclassical family on society are many. Individual rights are principally protected over the rights of the family as an organism. Legal tenets are drawn up to protect the individual rights in this case. The resulting kinds of goods cause segmentation between ethical goods desired by conservatism and individual preferences. Thus individual preferences are extended socially.

\section{The Socioeconomic Consequences of the Islamic Case}

The IIE-learning nature of decision-making in the Islamic family relegates individual rights based on self-interest to family guidance against unethical issues. In all ethical issues the collective will of the members guides and moulds the preferences of the individual members according to the Shari'ah rules. Such rules are inspired within the family discourse by the principal. Consequently, goods and services as common benefits replace competing markets. The legal tenets of the Shari'ah prohibit unethical and immoral goods to be consumed, produced, exchanged and traded.

Ethical deontological consequentialism of the market place (Sen, 1985) is good for all. Hence the resulting socioeconomic goods mobilize the spending power of the household in the economy through individuals who are established in the nuclear family environment for realizing the greatest degree of economic growth, productivity, stability and prosperity. Unethical markets are costly because of their price-discriminating behaviour in differentiated markets. Market segmentation is thus deepened.

The Head of the Family's and Islamic Inter-generational (Grandfathers and Grandchildren) Preference Effects on Household Well-being and its Socioeconomic Effects

Inter-generational generalization of familial decision-making along the IIE-learning process model is tied to the inter-generational extension of $\{\theta, \mathbf{x}(\theta)\}$-values. Note that time in the intertemporal 
framework now enters the analysis merely as datum to record the nature of co-evolution of $\{\theta, \mathbf{x}(\theta)\}$-values. The substantive effect on consensual decision-making is caused by knowledge-flows toward attaining simulated values of $W(\theta, \mathbf{x}(\theta))$. In the inter-generational nexus of the IIE-learning process methodology, $\mathrm{W}(\theta, \mathbf{x}(\theta))$ acts as a measure to evaluate the attained levels of unity of knowledge spatially (family and socioeconomics) and inter-generationally as well. In other words, in the inter-generational familial decision-making model according to the IIE-learning process the important point to observe is the generation-to-generation (i.e. process-to-process) continuity of the responsible and integrated behaviour in the IIE-model. A long haul of intertemporal simulation is thus replaced by sequential simulation on a learning-by-doing basis across the IIE-learning processes.

With regards to the inter-generational continuity of the Islamic family (grandchildren relations) the Qur'an declares (52:21): "And those who believe and whose families follow them in Faith, -- to them shall We join their families: nor shall We deprive them (of the fruits) of aught of their works: (Yet) is each individual in pledge for his deeds." The exegesis of this verse is that ethical bonds enhance intergenerational family ties as the essence of unity of the IIE-learning type preferences guided by the divine law. Furthermore, in such learning processes individual moral capacity interacts with the familial and socioeconomic structures.

Contrarily, the Qur'anic edict is also pointed out on the consequences of the breakdown of familial ties. The Qur'an establishes this rule in reference to the wife of Prophet Lot (11:81-82) and the wife and son of Prophet Noah (11:45-46; 66:10). These were lewd persons and therefore barred from Islamic family communion. Contrarily, even though Pharaoh was the archenemy of God, yet Pharaoh's wife was of the truthful. Thereby, she was enjoined with the family and community of believing generations. The same is true of the blessed Mary (Qur'an, 66:11-12).

In formal sense we now drop the suffixes in model (8) and generalize the expression for both intra- and inter- generational evolutionary cases. Expression (8) can be easily symbolized for individuals, households and heads for j-generations by a further extension using $\mathrm{j}$-subscript. The method of derivation is similar to (8).

Consider now the following differentiation in respect to the spacetime extension of $\theta$-values:

$\mathrm{dSW} / \mathrm{d} \theta>0 \rightarrow(1-\lambda)\left(\mathrm{dW}_{\mathrm{h}} / \mathrm{d} \theta\right)+\lambda\left(\mathrm{dW}_{\mathrm{H}} / \mathrm{d} \theta\right)+\left(\mathrm{W}_{\mathrm{H}}-\mathrm{W}_{\mathrm{h}}\right)(\mathrm{d} \lambda / \mathrm{d} \theta)>0$. 
Since, $(1-\lambda)\left(\mathrm{dW}_{\mathrm{h}} / \mathrm{d} \theta\right)>0 ; \lambda\left(\mathrm{dW}_{\mathrm{H}} / \mathrm{d} \theta\right)>0$ due to the monotonic knowledge $(\theta)$ effect, the degree of the positive value of (9) is determined by the sign of $\left(\mathrm{W}_{\mathrm{H}}-\mathrm{W}_{\mathrm{h}}\right)$, with $(\mathrm{d} \lambda / \mathrm{d} \theta)>0$ as a shift effect in social well-being. If $\left(\mathrm{W}_{\mathrm{H}}-\mathrm{W}_{\mathrm{h}}\right)>0$, the higher will be the positive value of $\mathrm{dSW} / \mathrm{d} \theta$.

Furthermore, from $\left(\mathrm{W}_{\mathrm{H}}-\mathrm{W}_{\mathrm{h}}\right)$ we obtain,

$$
\begin{aligned}
& \left(\mathrm{dW}_{\mathrm{H}} / \mathrm{d} \theta-\mathrm{dW}_{\mathrm{h}} / \mathrm{d} \theta\right)=\left(\partial \mathrm{W}_{\mathrm{H}} / \partial \theta-\partial \mathrm{W}_{\mathrm{h}} / \partial \theta\right)+ \\
& {[(\partial \mathrm{WH} / \partial \mathrm{Sp})-(\partial \mathrm{Wh} / \partial \mathrm{Sp})] \cdot(\mathrm{dSp} / \mathrm{d} \theta) .}
\end{aligned}
$$

The sign of (10) can be positive or negative. In the case of a positive sign we infer that the perception of the heads (principals) of the inter-generational families on well-being increases more than the members' well-being function as knowledge increases in the intergenerational family nexus. Thus the cumulative result of knowledge, communion and co-evolution is repeated inter-generationally (that is over inter-generational grandfathers and grandchildren). Likewise, socioeconomic consequences are similarly co-evolved.

Furthermore, since $\operatorname{Sp}(\theta)$ is a positive function of $\theta$ in view of the ethics of the Qur'an that encourages spending on the goods things of life, but in moderation, $\left[\left(\partial \mathrm{W}_{\mathrm{H}} / \partial \mathrm{Sp}\right)-\left(\partial \mathrm{W}_{\mathrm{h}} / \partial \mathrm{Sp}\right)\right]>0$ due to the effect of increases in $\theta$-values on the principals' higher perception of family well-being inter-generationally. Consequently, $\left(\mathrm{dW}_{\mathrm{H}} / \mathrm{d} \theta-\mathrm{dW}_{\mathrm{h}} / \mathrm{d} \theta\right)>$ 0 . So is, $\left(\mathrm{W}_{\mathrm{H}}-\mathrm{W}_{\mathrm{h}}\right)>0$, on the basis of the inter-generational well-being role of the family heads.

From the last two conditions we obtain the expression,

$$
\mathrm{W}_{\mathrm{H}}=\mathrm{a} \cdot \mathrm{W}_{\mathrm{h}}^{\mathrm{b}}, \mathrm{a}, \mathrm{b}>1 .
$$

$\mathrm{a}, \mathrm{b}$ are functions of $\theta$ and $\lambda(\theta)$, and are thereby learning-shift parameters in $\mathrm{W}_{\mathrm{h}}$ and $\mathrm{W}_{\mathrm{H}}$ as the inter-generational IIE-learning processes deepen in the family-socioeconomic circular causation interrelations.

\section{Conclusion}

The formalism of this paper explains that the IIE-learning type preferences formed in the midst of the family and its consequential socioeconomic linkages have important circular causal meaning. 
Such relations in systemic unity of knowledge play a significant role in the establishment of appropriate markets rather than leaving market forces to self-interest and consumer sovereignty. The triangular relationship between individuals, the household, and the socioeconomic order is continuously renewed and reproduced, giving evolutionary momentum to each of the agencies in this kind of circular causation, both intra- and inter-generationally.

The circular causation based on the IIE-learning process methodology of unity of systemic knowledge between individuals, family and the socioeconomic order can be treated as the domain of important institutional and policy formulation for ethical guidance and sustainability inter-generationally (over populations of grandfathers and grandchildren). Examples of such programmes and policies are the development of community centers for human resource development for sustaining inter-generational sustainability of ethics and values, guidance on spending on the good things of life, and inculcating ecological consciousness on the production and consumption of common goods for social well-being (Imam Shatibi trans. Draz, undated). Such efforts can be extended to the global management of development regimes that combine the ethical values of the inter-generational family with the human and socioeconomic development process.

\section{End Note}

1. It can be shown that in the utilitarian formulation of social welfare function the consequences of methodological individualism pervading from preferences and individual utility to welfare function divide up both the agent space $(\mathrm{i}, \mathrm{h})$ and the commodities space $(\mathrm{A}, \mathrm{B}, \mathrm{C})$. Thereby the ultimate form of the utilitarian formulation is $\left.\sum_{\mathrm{i}} \mathrm{U}_{\mathrm{ih}}(\mathrm{A}, \mathrm{B}, \mathrm{C})\right]=\Sigma_{\mathrm{x}=\mathrm{A}, \mathrm{B}, \mathrm{C}}$ $\left.\sum_{\mathrm{i}} \mathrm{U}_{\mathrm{ih}}(\mathrm{A}, \mathrm{B}, \mathrm{C})\right]$ either linearly over $\{\mathrm{x}\}$ or independently over $\{\mathrm{A}, \mathrm{B}, \mathrm{C}\}$. Other formulation would not help in the formulation of the welfare function with the property of methodological individualism entrenched in it.

\section{References}

Arrow, K. J. (1951). Social choice and individual values. New York: John Wiley \& Sons.

Becker, G. S. (1974). A theory of marriage. Journal of Political Economy, II, 82(2), S11-26.

114 IJMS 18 (1), 99-115 (2011) 
Becker, G. S. (1981). Treatise on the family. Cambridge, Mass: Harvard University Press.

Becker, G. S. (1989). Family. In J, Eatwell, M. Milgate \& P. Newman (Eds.), The new palgrave: Social economics (pp. 64-76). New York: W.W. Norton.

Ben-Porath, Y. (1980). The F connection: families, friends, and firms and the organization of exchange. Population and Development Review, 6(1), 1-30.

Brennan, G., \& Buchanan, J. (2000). Modeling the individual for constitutional analysis. In The reason of rules, constitutional political economy (pp. 53-74). Indianapolis, IN: Liberty Fund.

Choudhury, M.A. (1995). The Qur'anic derivation of the epistemicontic circular causation model. In his The epistemological foundations of Islamic economic, social and scientific order, Vol. 4, Chapter 3, (Ankara, Turkey: Statistical, Economic and Social Research and Training Center for Islamic Countries.

Choudhury, M. A. (1996). A theory of social systems: Family and ecology as examples. Kybernetes: International Journal of Systems and Cybernetics, 25(5), 21-38.

Debreu, G. (1959). Mathematics. In Theory of value, Chapter 1, New York: John Wiley \& Sons.

Choudhury, M. A. (1999). A philosophico-mathematical theorem on unity of knowledge. Kybernetes: International Journal of Systems and Cybernetics, 28(6/7), 763-776

Sen, A. (1985). The moral standing of the market. In E.F. Paul. Jr., F.D. Miller, \& J. Paul (Eds.), Ethics and economics. Oxford: Basil Blackwell.

Sztompka, P. (1991). The model of social becoming. In Society in action: The theory of social becoming (pp. 87-199). Chicago: University of Chicago Press.

[Imam] Shatibi (trans. A. Draz) undated. Al-Muafagat Fil Usul AlShari'ah, Cairo, Egypt: Al-Maktabah Al-Tijariyyah Al-Qubra.

United Nations Development Program (UNDP). 1997-2000 annual issues. Human Development Report. New York: Oxford University Press.

World Bank. (2000). World Development Report 2000-2001. New York: Oxford University Press. 